\title{
A Corpus-Based Study of Gender Representation in Chinese EFL
}

\section{Textbooks}

\author{
Qiuna $\mathbf{L i}^{*}$ \\ Postgraduate student, School of English Education, Guangdong University of Foreign Studies, China. \\ *Corresponding Author: Qiuna Li, Postgraduate student, School of English Education, Guangdong \\ University of Foreign Studies, China
}

\begin{abstract}
Aiming to explore whether the Chinese government's attempt to promote a "gender-equal" society in the new era is reflected in the teaching materials, this paper investigates the gender representation in English as a foreign language (EFL) textbooks for high school in mainland China. The present study made an analysis of one popular series of English language textbooks published in 2004 for local Chinese students with corpus linguistic tools (e.g. concordancing, keyword in context) to investigate the ratio of female-to-male appearances, the extent of use of gender-neutral and gender-marked constructions, the order of appearance of women, and men. The findings suggest that gender equity was tried to promote.
\end{abstract}

Keywords: Gender representation, EFL textbooks, corpus-based

\section{INTRODUCTION}

In recent years more and more international organizations, researchers have become more interested in the area of gender and education, in response to the international human rights programmes which aim to bring about "gender equality in and through education for females and males" (Mustapha \& Mills, 2015, p. 9). Mustapha and Mills (2015) argue that "working towards gender equality in education should not only focus on equal access to or provision of education to men and women", but also give further attention to "the content of education and the hidden curriculum" (p. 12).

Language teaching and learning are not ideologically neutral practices; they are located within specific political, historical and sociocultural contexts, all of which are "mediated through the textual and visual worlds of textbooks" (Curdt-Christiansen \& Weninger, 2015, p. 1). In the school educational materials transmit a large part of the social values and attitude to the young (Richardson, 1983, cited from Li, 2016). Thus, they are recognized as "the first official agent and the most powerful engine" for gender socialization (Foroutan, 2012, p. 771). It is therefore important to understand how foreign language textbooks relate to an contribute to broader societal objects (Yang, 2011).

Traditionally China has been a male-dominated society, treating the two genders unequally in the social, economic and political domains, being influenced by the Confucian culture and values. Although from the foundation of PRC in 1949 the official status of women began to improve and they gained a legal status previously denied them (Fang, Granrose \& Kong, 2005), the belief that 'men are superior, women are inferior' is still deeply rooted in Chinese society (Fang, 2005).

Under the ideology of Communism and the influence of the international feminist movement, there has been a series of political endeavors since the 1990s to promote gender equality in China. For International Journal on Studies in English Language and Literature (IJSELL)

Page | 15 
instance, in 1992 the PRC promoted the Law on the Protection of Women's Rights and Interests; in 1995 the Program for the Development of Chinese Women (1995-2000) (Fang, 2005). Although women did not attain full equality with men because it was difficult to change the customs and attitudes shaped by Confucianism which had dominated China for over 2000 years (Hooper, 1975), Chinese women embraced a new notion of femininity. As a result, a traditional conception of womanhood was revised, and some new role models were constructed, for example, the coexistence of "virtuous wife and kind mother" with "professional women" (Zhang, 2003, p. 214, cited from Li, 2016, p. 479).

In this context, to what extent is the gender-equality promoted in contemporary China? Textbooks provide a useful means to understand the social, political and economic settings. In addition, as Bag and Bay yurt (2008) stated, representations of gender in textbooks explicitly or implicitly convey messages to students about attitudes towards various roles in the reproduction of gender roles within society. Informed by the corpus-based approach, the purpose of this article is to examine a textbook series used in the high school in China on the issue of to what extent these textbooks are consistent with the promotion of equality and equal opportunities.

\section{LITERATURE REVIEW}

In the era of increasing globalization, English, as a Lingua Franca, is the most commonly taught second or foreign language in different types of educational institutions. Against this backdrop, EFL textbooks have attracted much attention from scholars. In terms of the ways in which women and men are represented in these textbooks gender representation has gained attention from the end of the last century (Porreca, 1984; Lee \& Collins, 2009; Yang, 2011; Namatende-Sakwa, 2018).

Over the past three decades, textbook studies on gender construction have provided both content and linguistic analyses of written discourse and pictures (e.g. Cincotta 1978; Evans and Davis 2000; Kobia 2009; Lee \& Collins, 2009, 2010; Sunderland 2000; Yang, 2011). These studies include investigations of gender stereotyping, male firstness, sexist language. Common findings include the use of pseudogeneric pronouns, underrepresentation of females, descriptions of women and women engaged in stereotypical activities, the ordering of men before women, descriptions of men as powerful, brave and adventurous and of women as emotional, weak, submissive and dependent. While these studies were conducted based on content and manual methods of numbering, which may make limitations in the findings.

The corpus-based study is performed with the help of a computer with specialized software by taking into account the frequency of the phenomena investigated. Carroll and Kowitz's (1994) pioneering corpus study demonstrated the effectiveness of using corpus tools including frequency counts, distributional analysis, collocation and Key Word in Context (KWIC) concordances to study gender construction in textbooks. Their findings show that corpus-based approaches, such as KWIC (Key Word in Context) and collocational analysis, can reveal gender representation and even gender stereotyping. Following Carroll and Kowitz (1994), studies of gender representation in different genres and in different contexts were conducted.

\section{The Present Study}

The purpose of this study is to compare how women and men are represented in one popular series of Chinese EFL textbooks published by the People Education Press (PEP) for high school students. The study is regarded as important for the following reasons. First, the Chinese government has placed more emphasis on the integration of moral education within the curriculum. While the hidden curriculum relating to gender construction in school textbooks may have some influence on the students' stereotypical thinking, their views of themselves and the opposite sex, even their career choices (Lee \& Collins, 2015; Witt, 2001). Second, although the Chinese government has made effort 
to guarantee gender equality from the foundation of PRC, it has been argued that there is still a gap between the reality and the ideals, for instance, the gender biases on the job market, the differences in the income between women and men. So far many studies on gender representation from other contexts, for instance, Japan (Lee, 2016), Uganda (Namatende-Sakwa, 2018), Turkey (Bag \& Bayyurt, 2015), Kenya (Kobia, 2009), however, relatively less quantitative evidence from Chinese contexts.

As mentioned previously, the purpose of this study is to reveal the gender representation embedded in EFL textbooks by tracing the frequency of recurring linguistic evidence in the corpus. To be specific, the present study seeks to answer the following research questions:

1) What is the ratio of female-to-male appearances in the PEP textbooks?

2) To what extent are gender-neutral and gender-marked constructions used?

3) What are the common adjectives used to describe women and men in the textbooks?

4) What is the order of appearance of women and men when both are referred to?

5) What are the common types of occupations associated with women and men?

\section{METHOD}

\subsection{Sample}

One popular series of EFL textbooks for high school students officially published in China were chosen as a sample for this study. They are New Senior English for China by People Education Press (PEP): Student's Books 1-5 (compulsory).

Table4.1. EFL textbooks analysed

\begin{tabular}{|l|l|l|l|l|}
\hline Textbook & Units & Pages & Word Types & Word Tokens \\
\hline PEP1 & 5 & 77 & 1475 & 6555 \\
\hline PEP2 & 5 & 77 & 1405 & 6658 \\
\hline PEP3 & 5 & 77 & 1595 & 7895 \\
\hline PEP4 & 5 & 77 & 1551 & 6411 \\
\hline PEP5 & 5 & 77 & 1747 & 7475 \\
\hline Total & 25 & 385 & & 34994 \\
\hline
\end{tabular}

All the scanned textbooks were converted into plain text format with the help of specific software. For the sake of better understanding the contents of the textbooks and further content analysis, the researcher has checked the accuracy of the converted file through line-by-line reading and revising. Consequently, a specific-purpose corpus of PEP EFL textbooks (PEP Corpus) for high school students was constructed. Altogether, the corpus contains 34994 tokens. Table 1 illustrates the components and composition of the PEP Corpus.

As seen from Table 4.1, the PEP corpus includes 5 compulsory books from this series. For the purpose of this study, the researcher included texts, reading passages, dialogues, paragraphs as contents of the corpus, considering that they contain texts "where ideologies and values are more easily detected" (Hong \& He, 2015, p. 94). The category of "Texts" refers to passages for intensive reading purpose in the student's book, "Reading passages" refers to the passages for extensive reading purpose in the "Workbook" part, while "Paragraph" refers to the reading materials in the exercises which contain gender markers. The researcher did not consider other parts, such as vocabulary, grammar and exercises with gap-filling since "corpus analysis works best with connected text where lexico-grammatical patterns can surface" (Hong \& He, 2015, p. 94). 
In addition, the following issues should be paid attention: 1) pictures and other visual images were not analyzed in this study, considering their relatively lower coverage rate in the textbooks, 2) the inclusion of the two textbook series is pursuing the representativeness and size of the corpus rather than the comparison of different series.

\subsection{Method of Analysis}

The main method of this study is quantitative in nature combining a corpus-based approach with content analysis as an auxiliary explanation, in response to "the criticism of the earlier gender studies" concerning the reliability (Lee, 2016, p. 385). The data analysis procedure consists of two steps: corpus-based analysis and content analysis.

As the first analytic step, AntConc, a concordance corpus tool, was employed to investigate the linguistic evidence of gender representation in the EFL textbooks. The Concordance Tool could be used to find the frequency counts of selected words and to organize data in a Keyword list (KWIC) so that the collocation features could be identified (Lee, 2016). In order to find the linguistic evidence of gender representation, several categories of gender markers were selected (see Table 4.2, adapted from Lee, 2016).

Table4.2. Methods of analysis

\begin{tabular}{|c|c|c|}
\hline Categories & Criteria & Codes \\
\hline $\begin{array}{l}\text { Female and male appearances (RQ } \\
\text { 1) }\end{array}$ & $\begin{array}{l}\text { Frequency of selected gendered words } \\
\text { (e.g. wife/wives/wife's/wives', husband, girl, } \\
\text { boy, man, woman, etc.) } \\
\text { Frequency of occurrence of feminine } \\
\text { pronouns (she, her, hers, herself) and } \\
\text { masculine pronouns (he, him, his, himself) }\end{array}$ & $\begin{array}{ll}\text { - } & \text { Female } \\
\text { - } & \text { Male }\end{array}$ \\
\hline $\begin{array}{l}\text { Gender-neutral and gender-marked } \\
\text { constructions (RQ 2) }\end{array}$ & $\begin{array}{l}\text { Frequency of occurrence of } \\
\text { pseudo-generic man/men, the compound } \\
\text { words ending with a masculine morpheme } \\
\text { (i.e. -woman/women, -girl(s), mistress(es)) } \\
\text { and their corresponding gender-neutral } \\
\text { counterparts } \\
\text { Frequency of occurrence of } \\
\text { gender-inclusive paired pronouns (he or she, } \\
\text { her/him, etc.) }\end{array}$ & $\begin{array}{ll}\text { - } & \text { Gender-neutral } \\
\text { - } & \text { Gender-marked }\end{array}$ \\
\hline Attributes (RQ 3) & $\begin{array}{l}\text { Adjectives collocating with selected } \\
\text { gendered nouns and their plural forms } \\
\text { (woman, man, boy and girl), and the } \\
\text { pronouns he and she }\end{array}$ & $\begin{array}{ll} & \text { Male } \\
- & \text { Female }\end{array}$ \\
\hline Order of appearance (RQ 4) & $\begin{array}{l}\text { Order of mention of men and women in a } \\
\text { phrase coordinated by and/or }\end{array}$ & $\begin{array}{ll}\text { - } & \text { Female first } \\
\text { - } & \text { Male first }\end{array}$ \\
\hline $\begin{array}{l}\text { The kinds of occupations } \\
\text { associated with gender (RQ 5) }\end{array}$ & $\begin{array}{l}\text { Through an analysis of the pronouns he and } \\
\text { she. }\end{array}$ & \\
\hline
\end{tabular}

\subsection{Reliability Issues}

Though data analysis in this research was assisted by corpus tools, the coding and categories were mainly done manually. Some inconsistencies may occur when categorizing themes, especially in the case of ambiguity of word meaning or when coders interpret the data differently. To ensure high 
reliability, the coding and categorizing were performed separately by the researcher of this study and an assistant. When discrepancies occurred, the researchers discussed them until they could come to an agreement to ensure high inter-coder reliability.

\section{RESULTS AND DISCUSSION}

\subsection{Female and Male Appearances}

To answer the first research question "What is the ratio of female-to-male appearances in the PEP textbooks?", the frequencies of some selected gendered words (e.g. man/men, woman/women, mother, father, boy, girl) were recorded, as shown in Table 5.1. The ratio of female- to male-gendered terms was 1:1.515. This ratio indicates the female under-representation in PEP series textbooks.

The study also included frequency counts of feminine and masculine pronouns (see Table 5.2). The ratio of 2.133:1 shows that there were substantially more occurrences of masculine pronouns than feminine pronouns. This result is consistent with the finding on gendered vocabulary.

Table5.1. Frequencies of selected gendered words

\begin{tabular}{|l|l|l|l|}
\hline Male & PEP 1-5 & Female & PEP 1-5 \\
\hline man/men & 46 & woman/women & 25 \\
\hline Mr & 14 & Ms/Miss/Mrs & 8 \\
\hline boy & 6 & Girl & 10 \\
\hline father & 5 & Mother & 5 \\
\hline Dad & 7 & Mum (Mummy) & 3 \\
\hline Husband & 3 & wife & 2 \\
\hline son & 6 & daughter & 2 \\
\hline Brother & 9 & Sister & 6 \\
\hline Grandfather & 1 & Grandmother & 1 \\
\hline grandson & 1 & Granddaughter & 2 \\
\hline gentleman & 5 & lady & 4 \\
\hline Total & 103 & Total & 68 \\
\hline
\end{tabular}

Table5.2. Masculine and Feminine Pronouns

\begin{tabular}{|l|l|l|l|l|l|l|l|l|l|l|}
\hline & \multicolumn{3}{|l|}{ Nominative } & \multicolumn{2}{l|}{ Accusative } & \multicolumn{2}{l|}{ Genitive } & \multicolumn{2}{l|}{ Reflexive } & \multicolumn{2}{l|}{ Total } & \\
\hline PEP & he & she & him & her & his & her/hers & himself & herself & Masculine & Feminine \\
\hline Total & 326 & 134 & 57 & 73 & 152 & 46 & 9 & 2 & 544 & 255 \\
\hline
\end{tabular}

\subsection{Gender-Neutral and Gender-Marked Vocabulary}

To compare the incidence of gender-marked and gender-neutral terms in this set of textbooks, a search was conducted for pseudogeneric man, the compound words ending with a masculine morpheme (i.e. -man/men, -master) and a feminine morpheme (i.e. -woman/women, -girl[s], -ress[es]) and their corresponding gender-neutral counterparts. The findings are summarized in Table 5.3.

The study recorded a total of 66 gender-marked terms in PEP series EFL textbooks, and the corresponding gender-neutral terms found were 250 . This finding suggests that this series textbooks' authors tend to use more gender-neutral terms, for example, people, person(s), human in place of man. However, it is worth noting that some gender-neutral terms (e.g. athlete, owner, actor) are more often used in place of their gender-marked counterparts (e.g. sportsman, hostess, actress). While some other unmarked terms (e.g. servant) are less often used in place of their marked counterparts (e.g. waiter). This may be concerned with linguistic issues. 
A Corpus-Based Study of Gender Representation in Chinese EFL Textbooks

Table5.3. Gender-Neutral and Gender-Marked Vocabulary

\begin{tabular}{|l|l|l|}
\hline Vocabulary (the plural forms included) & Gender-neutral (N)/ Gender-marked (M) & PEP \\
\hline pseudogeneric man & $\mathrm{M}$ & 0 \\
\hline people & $\mathrm{N}$ & 177 \\
\hline Person & $\mathrm{N}$ & 18 \\
\hline Human/human being & $\mathrm{N}$ & 13 \\
\hline Policeman & $\mathrm{M}$ & 1 \\
\hline police & $\mathrm{N}$ & 2 \\
\hline sportsman & $\mathrm{M}$ & 3 \\
\hline athlete & $\mathrm{N}$ & 9 \\
\hline owner & $\mathrm{N}$ & 16 \\
\hline hostess & $\mathrm{M}$ & 7 \\
\hline God & $\mathrm{N}$ & 3 \\
\hline goddess & $\mathrm{M}$ & 3 \\
\hline queen & $\mathrm{M}$ & 11 \\
\hline king & $\mathrm{M}$ & 22 \\
\hline prince & $\mathrm{M}$ & 2 \\
\hline princess & $\mathrm{M}$ & 2 \\
\hline
\end{tabular}

\subsection{Adjectives}

To answer the third research question "What are the common adjectives used to describe women and men in the textbooks?", a collocational analysis was conducted to investigate the types of properties and characteristics most commonly ascribed to males and females. All the personal predicative and attributive adjectives used with pronouns (she, he) and the gendered nouns (man/men, woman/women, $\operatorname{girl}(\mathrm{s})$ and boy(s) were recorded. Table 5.4 illustrates the findings.

Table5.4. Personal Adjectives Collocating with Female- and Male-Referring Expressions

\begin{tabular}{|c|c|c|c|}
\hline Category & Adjective & Male & Female \\
\hline \multirow{3}{*}{ Age } & 1. young & 7 & 1 \\
\hline & 2. $\quad$ old & 4 & 0 \\
\hline & 3. little & 1 & 0 \\
\hline \multirow{3}{*}{ Physical appearance } & 4. big (size) & 1 & 0 \\
\hline & 5. beautiful & 0 & 1 \\
\hline & 6. tall & 1 & 0 \\
\hline \multirow{7}{*}{ Personality } & 7. good & 2 & 0 \\
\hline & 8. brave & 1 & 0 \\
\hline & 9. wise & 1 & 0 \\
\hline & 10. generous & 3 & 0 \\
\hline & 11. quiet & 1 & 0 \\
\hline & 12. reliable & 0 & 1 \\
\hline & 13. unfair & 1 & 0 \\
\hline \multirow{2}{*}{ Intelligence } & 14. foolish & 1 & 0 \\
\hline & 15. clever & 2 & 0 \\
\hline \multirow{2}{*}{ Physical state } & 16. fast & 1 & 2 \\
\hline & 17. ill & 1 & 0 \\
\hline
\end{tabular}


A Corpus-Based Study of Gender Representation in Chinese EFL Textbooks

\begin{tabular}{|c|c|c|c|}
\hline \multirow{2}{*}{ Wealth } & 18. poor & 1 & 0 \\
\hline & 19. rich & 1 & 0 \\
\hline \multirow{11}{*}{ Emotions } & 20. calm & 1 & 0 \\
\hline & 21. hopeful & 1 & 0 \\
\hline & 22. happy & 1 & 2 \\
\hline & 23. alone & 1 & 0 \\
\hline & 24. homeless & 1 & 0 \\
\hline & 25. guilty & 1 & 0 \\
\hline & 26. overjoyed & 1 & 0 \\
\hline & 27. excited & 0 & 1 \\
\hline & 28. angry & 0 & 2 \\
\hline & 29. stubborn & 0 & 1 \\
\hline & 30. thrilled & 0 & 1 \\
\hline \multirow{7}{*}{ Evaluation } & 31. popular & 1 & 0 \\
\hline & 32. best known & 1 & 0 \\
\hline & 33. great & 1 & 1 \\
\hline & 34. famous & 1 & 1 \\
\hline & 35. lucky & 1 & 0 \\
\hline & 36. right & 0 & 1 \\
\hline & 37. proud & 0 & 1 \\
\hline Total & & 41 & 16 \\
\hline
\end{tabular}

One notable aspect of the findings is that twice as many adjectives were used to portray men as women in this series of EFL textbooks (41:16). Another notable aspect of the findings is that there were half the numbers of adjectives were concerned with emotions among the limited range of adjectives associated with female characters. This may have the effect of making them appear more gender-stereotyped.

Of the 37 adjectives found, 24 were used to describe men, 8 to describe women and 5 to describe both genders. Beautiful, reliable, excited, angry, stubborn, thrilled, right and proud collocated exclusively with females, suggesting a concern with two general properties: appearance, emotionality. On the other hand, males were more often associated with success (famous, well-known, popular), wealth (rich, poor, generous), as well as physical and mental strength (good, wise, brave). The findings of the present study is persistence of the problems of gender imbalance and gender stereotyping associated with adjectives noted in Lee \& Collins's (2015) study.

\subsection{Order of Mention}

In previous investigations (e.g. Lee \& Collins, 2016; Lee, 2016) the researchers have suggested the conventional male-first order of mention through observation of EFL textbooks corpora in Hong Kong (Lee \& Collins, 2016) and in Japan (Lee, 2019). While the paired expressions identified in the present study were relatively fewer, as shown in Figures 5.1 - 5.6. Although these figures have shown a higher ratio of male firstness (eight instances among the total ten), it may be hasty to assert gender inequality based on the limited evidence.

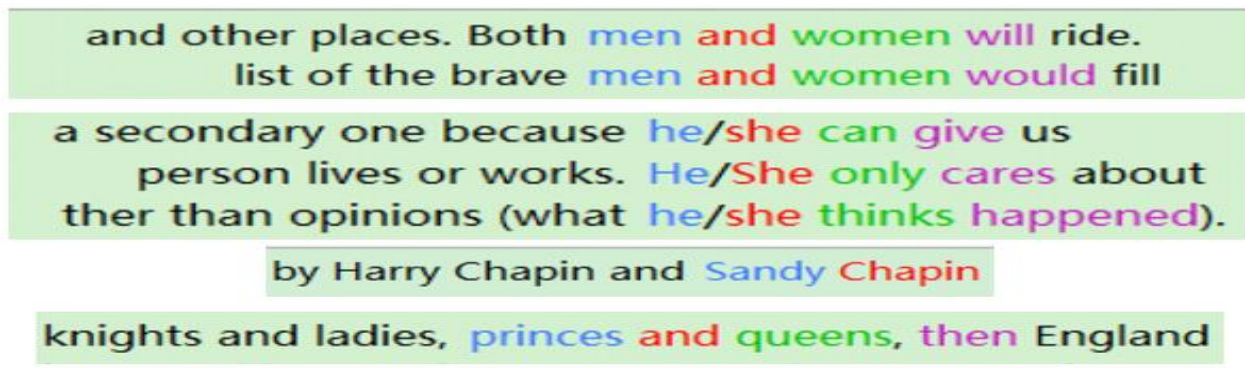

Figures5.1-5.4. Male Firstness 


\section{1/300B (Earthtime) Dear Mum and Dad. I still}

\section{like Song Zuying or Liu Huan? To be honest,}

Figures5.5-5.6. Female Firstness

\subsection{Occupations of Males And Females}

Table5.5. Engagement and Activities Associated With He and She

\begin{tabular}{|c|c|c|c|c|c|}
\hline \multicolumn{2}{|c|}{ Activities associated with he } & \multirow{2}{*}{$\begin{array}{l}\text { Freq. } \\
15\end{array}$} & \multicolumn{2}{|c|}{ Activities associate with she } & \multirow{2}{*}{$\begin{array}{l}\text { Freq. } \\
12\end{array}$} \\
\hline \multirow{6}{*}{ "Saying" } & say & & "Saying" & say & \\
\hline & tell & 9 & & tell & 4 \\
\hline & call & 3 & "Emotional state" & want & 1 \\
\hline & advise & 2 & "Senses" & see & 3 \\
\hline & ask & 2 & & feel & 2 \\
\hline & explain & 2 & "Cognitive" & discover & 2 \\
\hline \multirow{7}{*}{$\begin{array}{l}\text { "Emotional } \\
\text { state" }\end{array}$} & think & 10 & "Action" & give & 6 \\
\hline & want & 5 & & help & 3 \\
\hline & believe & 3 & & spend & 3 \\
\hline & find & 3 & & marry & 2 \\
\hline & wonder & 2 & & meet & 2 \\
\hline & decide & 2 & & visit & 2 \\
\hline & look forward & 2 & "Engagement" & work & 3 \\
\hline \multirow{6}{*}{ "Senses" } & see & 6 & & & \\
\hline & feel & 4 & & & \\
\hline & hear & 3 & & & \\
\hline & notice & 2 & & & \\
\hline & smile & 2 & & & \\
\hline & look at & 2 & & & \\
\hline \multirow{3}{*}{ "Cognitive" } & know & 6 & & & \\
\hline & discover & 2 & & & \\
\hline & suggest & 2 & & & \\
\hline \multirow{6}{*}{ "Engagement" } & do & 14 & & & \\
\hline & make & 10 & & & \\
\hline & work & 7 & & & \\
\hline & study & 2 & & & \\
\hline & learn & 2 & & & \\
\hline & win & 2 & & & \\
\hline \multirow{7}{*}{ "Action" } & give & 6 & & & \\
\hline & go & 5 & & & \\
\hline & come & 4 & & & \\
\hline & walk & 4 & & & \\
\hline & leave & 3 & & & \\
\hline & write & 4 & & & \\
\hline & show & 3 & & & \\
\hline
\end{tabular}




\begin{tabular}{|c|c|c|c|c|}
\hline & drive & 2 & & \\
\hline & eat & 2 & & \\
\hline & follow & 2 & & \\
\hline & throw & 2 & & \\
\hline & kill & 2 & & \\
\hline & become & 4 & & \\
\hline & get & 3 & & \\
\hline "Changing" & grow & 3 & & \\
\hline & change & 2 & & \\
\hline & fell & 2 & & \\
\hline Total & 45 & & Total & 13 \\
\hline
\end{tabular}

To investigate what activities the two genders are likely to be engaged in, the clusters tool was employed to identify the semantic categories of the verbs and complements collocating with the nominative pronouns he and she. Specifically, the researcher set the "Cluster Size" at two, three, five respectively in order to better identify the collocating with he and she verbs associated with activities. The findings were demonstrated in Table 5.5, listing all the identified verbs with frequency of 2 and higher. The researcher excluded the verbs which appeared only one time based on previous researchers' practices (e.g. Lee \& Collins, 2015).

The findings, as presented in Table 4.5, indicate the presence of gender bias to some extent. First, females tend to be portrayed in a limited range of activities, including say, want (to do something), give, spend (time), work and visit. Men, on the other hand, are presented as being engaged in a wider range of activities: make, work, study, win, drive, think, decide, say (including tell, explain, advise). However, it will be doubted that the obvious difference in ratio of activities may be caused by the difference of frequency counts of masculine and feminine pronouns. Correspondingly, the researcher compared the former ratio (3.462:1) with the later (2.433:1), therefore, the researcher argues that the activities engaged in by women were fewer compared to men. Nevertheless, challenges to women's traditional roles could still be found in this series, for example, women work, help others, visit (or meet) with others.

\section{CONCLUSiON}

This study has provided insights into gender representation in Mainland China high school English-language textbooks published in 2004. It represents an important contribution to the under-researched area of gender representation in textbooks in Asian countries. The present study suggests that males and females were unequally represented in PEP series of EFL textbooks for high school students in China. Although the writer of this series tries to use more gender-neutral terms, the corpus-based evidences of selected gendered words, feminine and masculine pronouns, as well as the adjectives collocating with females and males indicate the unbalanced treatment of females and males in this series of textbooks.

The limitation of this study is that the selected textbooks from one series which was published in 2004 . In the future study more series of textbooks from the same or different contexts could be included in order to gain a more holistic and critical analysis of the gender construction in textbooks. On the one hand, we could conduct a comparative study of the same series published in different years, for example, between PEP EFL textbooks published in 2004 and in 2019. On the other hand, the comparative study could be conducted based on the larger corpora which consists of several popular series published in the same period in the Chinese context. 


\section{REFERENCES}

[1] Mustapha, A., \& Mills, S. (2015). Gender representation in learning materials in an international context. In S. Mills, \& A. Mustapha (Eds.), Gender representation in learning materials: International perspectives (pp. 9-18). New York: Routledge.

[2] Curdt-Christiansen, X. L., \& Weninger, C. (Ed.). (2015). Language, ideology and education London: Routledge.

[3] Richardson, L. (1983). Guidelines for evaluation of elementary textbooks. In L. Richardson \& V. Taylor (Eds.), Feminist frontiers II: Rethinking sex, gender, and society (pp. 74-78). Boston, MA: Addison-Wesley.

[4] Li, X. (2016) Holding up half the sky? The continuity and change of visual gender representation in elementary language textbooks in post-Mao China, Asian Journal of Women's Studies, 22:4, 477-496.

[5] Foroutan, Y. 2012. "Gender Representation in School Textbooks in Iran: The Place of Languages." Current Sociology 60 (6): 771-787.

[6] Yang, C. C. R. (2011) Gender representation in a Hong Kong primary English textbook series: the relationship between language planning and social policy, Current Issues in Language Planning, 12:1, 77-88.

[7] Fang, Y. Q., Granrose, C. S., \& Kong, R. V. (2005). National policy influence on women's careers in the People's Republic of China. In C. K. Granrose (Ed.), Employment of Women in Chinese Cultures: Half the sky (pp. 49-83). Cheltenham: Edward Elgar.

[8] Fang, Y. Q. (2005). Women's development in Hebei Province, PRC. In C. K. Granrose (Ed.), Employment of Women in Chinese Cultures: Half the sky (pp. 157-178). Cheltenham: Edward Elgar.

[9] Hooper, B. (1975). Women in China: Mao “v.” Confucius. Labour History, (29), 132-145.

[10] Zhang, J. H. (2003). Gender in post-Mao China. European Review, 11(2), 209-224.

[11] Bag, E., \& Bayyurt, Y. (2015). Gender representations in EFL textbooks in Turkey. In S. Mills, \& A. Mustapha (Eds.), Gender representation in learning materials: International perspectives (pp. 64-85). New York: Routledge.

[12] Porecca, K.L. 1984. Sexism in current ESL textbooks. TESOL Quarterly, 18, 4: 705-724.

[13] Lee, J.F.K., \& Collins, P. 2009. Australian English-language textbooks: The gender issues. Gender and Education, 21, 4: 353-370.

[14] Namatende-Sakwa, L. (2018). The construction of gender in Ugandan English textbooks: a focus on gendered discourses, Pedagogy, Culture \& Society, 26:4, 609-629

[15] Cincotta, M. S. 1978. Textbooks and their influences on sex-roles stereotypes formation. BABEL: Journal of the Australian Federation of MLTS Associations, 14(3): 24-29.

[16] Evans, L., \& Davies, K. 2000. No sissy boys here: A content analysis of the representation of masculinity in elementary school reading textbooks. Sex Roles, 42(3/4): 255-270.

[17] Kobia, J.M. (2009). Femininity and masculinity in English primary school textbooks in Kenya. The International Journal of Language Society and Culture, 28: 57-71.

[18] Lee, J.F.K., \& Collins, P. (2010). Construction of gender: A comparison of Australian and Hong Kong English language textbooks. Journal of Gender Studies, 19, 2: 121-137.

[19] Sunderland, J. (2000). Issues of gender representations in textbooks: A state of the art studies. Language Teaching, 33, 4: 203-223.

[20] Carroll, D., \& Kowitz, J. 1994. Using concordancing techniques to study gender stereotyping in ELT textbooks. In J. Sunderland (Ed.), Exploring gender: Questions and implications for English language education, pp. 73-82. New York: Prentice Hall. 
[21] Lee, J., \& Collins, P. (2015). Gender representation in Hong Kong primary English-language textbooks: a corpus study. In S. Mills, \& A. Mustapha (Eds.), Gender representation in learning materials: International perspectives (pp. 37-51). New York: Routledge.

[22] Witt, S.D. 2001. The influence of school texts on children's gender role socialization. Curriculum and Teaching, 16, 1: 25-43.

[23] Lee, F. K. J. (2016). Gender representation in Japanese EFL textbooks - A corpus study. Gender and Education, 1-17.

[24] Hong, H., \& He, X. (2015). Ideologies of monoculturalism in Confucius Institute textbooks: A corpus-based critical analysis. In Curdt-Christiansen, X. L., \& Weninger, C. (Ed.), Language, ideology and education (pp. 90-108), London: Routledge.

[25] Lee, F. K. J. (2019) in the pursuit of a gender-equal society: do Japanese EFL textbooks play a role? Journal of Gender Studies, 28:2, 204-217.

\section{AUTHOR'S BIOGRAPHY}

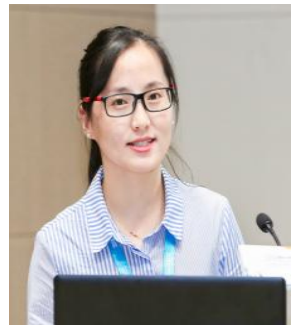

Qiuna Li, is a postgraduate student in the School of English Education at Guangdong University of Foreign Studies, China. She is interested in foreign language education policy, curriculum, discourse analysis and teacher development.

Citation: Qiuna Li. A Corpus-Based Study of Gender Representation in Chinese EFL Textbooks. "International Journal on Studies in English Language and Literature (IJSELL), vol 8, no.4, 2020, pp. 15-25. doi: http://dx.doi.org/10.20431/2347-3134.0804003.

Copyright: () 2020 Authors. This is an open-access article distributed under the terms of the Creative Commons Attribution License, which permits unrestricted use, distribution, and reproduction in any medium, provided the original author and source are credited. 